outer zone, so that steep edges and objects of high refractive index difference may still show a modified Becke line ; but the desired object may be practically free from it, dark contrast being produced instead.

The following incomplete statement indicates the angular values concerned. The maximum deviation that can be produced by a cylindrical object is that for a ray entering and emerging at the grazing angle and will equal $2(90-\theta)^{\circ}$, where $\theta$ is the critical angle. For refractive indices $1 \cdot 33$ (water) and, say, $1 \cdot 35$ (object), $2(90-\theta)$ is $20^{\circ}$ in the liquid. If the opaque $p$ art of the diaphragm at the back of the objective intercepts rays that occupy this angle, such an object will appear dark except at points near the centre. For low-power objectives with low numerical aperture, the angles that can be covered are much narrower than this, but the method will be sensitive to small differences in refractive index. Higher powers, on the other hand, with numerical aperture about $\mathbf{l} \cdot 0$, will accommodate annuli covering a wider angle that may approach $20^{\circ}$, and they can be made effective for objects of wider deviation.

The accompanying photographs illustrate the results obtainable with low- and medium-power objectives (Cooke, $25 \mathrm{~mm}$., $0.15 \mathrm{~N} . \mathrm{A}$. and $4 \mathrm{~mm}$. N.A. 0 65), by means of narrow conical illumination with opaque stops partly covering the back of the objective as shown in $a$ and $d$. In these cases the depth of focus is very small and only parts of the object can be in focus, the tendency being to obtain an 'optical section'. Phase-contrast photographs of kaolin were reproduced in Nature, 158, 621 (1946).

The comparison photographs $e$ and $i$ were taken with narrow conical illumination. This is probably the most satisfactory form of ordinary illumination for objects of small refractive index difference, since it gives a moderate Becke effect without undue loss of light, but the image is mainly due to this effect.

Photographs $c, f, g, h, j$ indicate that the contrast diaphragm causes no great injury to the resolution of details in the object. $k$ and $l$ were taken through the annulus and outer zone of the objective, used separately. Neither would supply the detail observed in $j$, although the only difference is that in $j$ both areas are open simultaneously. The improvement is presumably due to interference in accordance with Abbe theory.

In ordinary narrow-aperture illumination, a small object in liquid of lower refractive index appears light when the tube is raised, almost invisible when in the focal plane, and dark when the tube is lowered. For a simple isolated object the latter effect resembles that given by contrast methods, but is only produced when the object is somewhat out of focus. When the object is in the focal plane, the use of a contrast diaphragm produces a similar darkening, and the details are in focus. For a complex rugose (or finely granular) object such as the kaolin scales in $e$, the Becke lines overlap in the interior of the object areas, producing a confused mottling which in fact only an experienced observer would interpret as due to a solid object. It is in such cases that the use of contrast methods seems most likely to be advantageous.

The annulus in $d$ was purposely made narrow to test the effect on resolution. It is not suggested that this would be necessary in all cases.

This communication has been published by permission of the Director, Geological Survey and Museum.

\section{INDUSTRY AND RESEARCH IN THE SHEFFIELD AREA}

$T$ HE Federation of British Industries has been holding in recent months a series of conferences on that vital question of the present time, the dependence of progressive industry on research. One of these regional conferences was held in Sheffield on June 5 to discuss the bearing of research on industry in the case of the smaller manufacturing concerns. The problems were considered from two aspects: the first, at a morning session, presided over by Sir Walter Benton Jones, dealt with the part research could play in promoting industrial efficiency, exports and a higher standard of living, with special reference to the industrial problems of the Sheffield area. Sir Walter, in opening the meeting, directed attention to the valuable conclusions of previous conferences, and stated that industry values highly the growth of special research. The afternoon session, Lord Dudley Gordon being in the chair, was devoted to the case of the smaller manufacturing concern which could not afford the cost of a research department, and consideration was given to the research organisations and facilities which could serve it.

The subject of "Research and National Recovery" was discussed by Sir William Larke in a paper full of wise advice of an encouraging and stimulating character. He pointed out that our industrial production needs to be increased above that of 1938 by at least 25 per cent under conditions of a shortage of raw materials and man-power. These requirements point to the need for technical advances, at least as great as those which were achieved during the War. He regards shortage of coal as the principal factor preventing our economic recovery. This difficulty demands still more attention to efficient use, by increased supervision, by continuing to demand of the suppliers fuel of the appropriate quality, and by the provision of more efficient fuel-using plant. Further, our general production efficiency must be at a higher level than that of our competitors. The support of research and closer collaboration of all elements concerned with industry and research are necessary. A survey made by the Federation of British Industries of research activities in British industry has shown a total of some 40,000 staff, of whom 10,000 are graduates of a university or equivalent standard. The total expenditure by industry on research, Sir William said, has increased fourfold in the last ten years, and is now in excess of $£ 25,000,000$ per annum, or at least 0.5 per cent of the total value of our annual industrial production. This situation and the potentialities of rapid application of the results of research and discovery to the improvement of industrial efficiency should provide the means of strengthening our competitive power in world markets. The achievements in the face of the overwhelming difficulties of 1940 onwards give hopes of inspiration and encouragement for the future.

Dr. G. P. Jones, discussing the lessons of history in a paper entitled "The Historical Growth and Economic Development of Sheffield Industries", had perforce to limit his scope to steel-making and cutlery. He showed how much we are dependent on the competence of our forefathers, and in what degree an easy livelihood and survival of two terrible wars are owed to their efforts. The historical aspects of the question were also dealt with by Lord Dudley Gordon in reference to valuable contributions 
to industry which had been made by Sheffield metallurgists. These contributions, as it was put by Sir Charles Goodeve in his summing up of the discussion, showed that confidence is restored by the existence of a momentum of the past.

Prof. R. J. Sarjant, in a paper on "The Industrial Problems of the Sheffield Area and their Solution by Methods of Research", showed how complex the research problems of industry are becoming with the rapid advancement of engineering practice. While the laboratory is still the place for pioneer development, modern research has to proceed to the study of the maze of variables encountered in the plant. This entails the service of the balanced research team -trained research workers, observers and technicians-which in general can only be supplied by the larger research organisation, and in regard to the smaller firm can only be provided by co-operative action. The major problem at present appears to be the better utilization of existing resources. This involves co-ordination of effort, better training and adequate contacts between industrial and research personnel. There is, too, the place of the university, which is, so to speak, on the doorstep. Its function is to inspire the spirit of a 'divine discontent' so useful to research-mindedness, to foster the development of methods which apply to the solution of sociological and technical problems, and to be at the spear-point of the development of research.

Lord Dudley Gordon referred to the potentialities which lie in the institution of the Engineering Research Board. It is patent that demand for men, buildings and equipment has outstripped the supply. It is accordingly expedient to examine what can be done in the circumstances. Where there is no research department, there should be individuals who can collect and study new knowledge, and apply the findings of research done by others to immediate industrial problems. Internal questions of the attitude of management, psychological outlook and methods of organisation must be considered. There are valuable assets in the technical colleges, the scientific societies and advisory services to put inquirers in touch with sources of information. The Research Secretariat which the Federation of British Industries has set up is a valuable instrument in this last respect.

In a paper on "Sheffield Research Organisations, Facilities and Activities", Dr. W. J. Rees outlined the activities of the University, its functions and contributions in relation to the matters discussed, the achievements of the works' laboratories, the wide extent of the work of the research associations, and the facilities available in the technical industries and the efficient library services.

Dr. F. C. Lea finally tackled the main problem of the smaller firms, in a paper entitled "The Smaller Firm and its Application of Research". He took the view that of necessity the small firms have a real live interest in research; they have an essential place in the industrial structure; they can be helped and they can help themselves. The first essential is the need for adequate scientific and technical training of owners and managers. This means better technical colleges and more use to be made of them. These should be provided with staff and equipment to assist in solving the problems of the small firm. Managers should be familiar with what is being done not only in Great Britain but also in other countries. They should be ready, too, to buy new plant and to use new methods.
In the discussion which followed, many points of interest were raised, particularly around the matter of the fear which some managements have of admitting competitors to see what are considered to be secret processes. It was shown, however, that such fears are groundless, and that more is to be gained by accepting the opportunity of learning from others; the competitor usually already knows all about the 'secret' process. Dr. Maddocks referred to the high proportion of trained metallurgists who are being taken into the Armed Services, when industry requires them so urgently, and pressed that something should be done to remedy the position. Prof. Moore emphasized the need for 'putting over' the results of research; he rates it the major part of the problem. Finally, Mr. O. S. Brown, of the Department of Scientific and Industrial Research, outlined the many ways in which the Department is assisting in these matters. Thus help is always available for research in universities for "work of timeliness and promise". An information service has been set up to bring together the man with the problem and the man who can supply the solution. The aims are to create an organisation which is flexible and able to meet the varying needs of industry, to look for the gaps in the organisation and to consider how they can be filled.

In his summing up of the discussion, Sir Charles Goodeve hoped that the Federation would stimulate the examination of the questions discussed. Cooperative action, he said, is clearly ealled for, as well as more exertion. Much depends upon the technical knowledge of those in executive positions, since they must have sound discrimination in making their important decisions. The small firms may be facing a challenge greater than they have to-day. They should seek knowledge, cultivate a 'divine discontent' and have courage. They might not then long remain small.

\section{HARDENABILITY OF STEEL}

T $\mathrm{N}$ the spring of 1943 a small mission of British 1 metallurgists visited the United States and Canada to discuss the extent to which economy in the use of alloys required for the production of certain special steels could be still further increased. The problem arose from the fact that some of the alloying metals in common use in peace-time were not then available in quantity sufficient to meet the whole of the requirements of the Allies, and alternative steels had to be devised. A most comprehensive account of some of the work done in this direction is included in a "Symposium on the Hardenability of Steel" published by the Iron and Steel Institute, and discussed at a meeting of that Institute on May 14. It should be pointed out-a fact which was not always remembered during the actual discussion-that this work was done under the stress of war-time conditions and that, therefore, there are numerous problems which still await more detailed examination. Fundamental questions of the greatest interest have emerged, and many fields for further work opened up.

The major portion of the papers deal with the end-quench hardenability test-usually known by the name of the 'Jominy test'-the interpretation of the results obtained, and the possibility of using these to predict the extent to which bars of different diameter can be hardened. The influence of boron in increasing 